\title{
SPECTRUM OF NEOPLASTIC AND NON-NEOPLASTIC LESIONS ASSOCIATED WITH PREGNANCY- 5 YEARS EXPERIENCE IN A TERTIARY REFERRAL CENTRE
}

\author{
Kokila $K^{1}$, Kanchana M. $P^{2}$
}

${ }_{1}^{1}$ Postgraduate, Department of Pathology, Madras Medical College, Dr. MGR Medical University, Tamilnadu.

2 Professor, Department of Pathology, Institute of Obstetrics and Gynaecology \& Government Hospital for Women and Children, Dr. MGR Medical University, Tamilnadu.

\section{ABSTRACT}

\section{BACKGROUND}

The incidence of adnexal and non-adnexal masses in pregnancy appears to be increasing in line with the expanding use of antenatal ultrasound. Majority of such masses do not cause problems and persisting masses can lead to complications and may require emergency or elective surgical resection.

\section{MATERIALS AND METHODS}

In this study, we retrospectively analysed neoplastic and non-neoplastic lesions associated with pregnancy for a period of five years from May 2011 to May 2016 in Institute of Obstetrics and Gynaecology, Government Hospital for Women and Children, Egmore, Chennai. Our study population included all antenatal women with dysfunctional cysts, adnexal and non-adnexal masses. Most of these lesions were incidental and found during caesarean section while remaining patients underwent emergency laparotomy due to acute symptoms that endangered maternal and foetal life. We reviewed our medical records during the study period and details regarding patient age, clinical and histopathological nature of the lesions were collected.

\section{RESULTS}

There were 68,877 deliveries during the study period and 97 women were found to have these lesions, out of which 73 women had neoplastic lesions and 24 women had non-neoplastic lesions. Adnexal cysts were the most common non-neoplastic lesions associated with pregnancy. Benign lesions outnumbered the malignant counterparts. Uterine leiomyomas, benign ovarian surface epithelial tumours, sex cord stromal tumours and benign cystic teratomas were reported among benign neoplasms. Germ cell tumours were frequently encountered among malignancies, dysgerminoma being the commonest germ cell neoplasm. Two cases of bilateral Krukenberg tumour and one case of mixed germ cell tumour were recorded. We also reported a case of angiomyolipoma and welldifferentiated hepatocellular carcinoma which presented as haemoperitoneum during pregnancy.

\section{CONCLUSION}

Pregnancy is associated with various neoplastic and non-neoplastic lesions and requires early diagnosis and management for better foetal and maternal outcome.

\section{KEYWORDS}

Pregnancy, Leiomyomas, Angiomyolipoma, Dysgerminoma, Mixed Germ Cell Tumour, Hepatocellular Carcinoma, Krukenberg Tumour.

HOW TO CITE THIS ARTICLE: Kokila K, Kanchana MP. Spectrum of neoplastic and non-neoplastic lesions associated with pregnancy- 5 years experience in a tertiary referral centre. J. Evolution Med. Dent. Sci. 2016;5(95):6976-6981, D0I: 10.14260/Jemds/2016/1578

\section{BACKGROUND}

A number of neoplastic and non-neoplastic lesions are associated with pregnancy. Among non-neoplastic conditions, dysfunctional cysts are frequently encountered and most commonly identified at the time of caesarean section or puerperal sterilisation, at which time they can simply be drained or excised. Benign ovarian neoplasm and leiomyomas are also identified during pregnancy. Malignancies have an incidence of approximately 1 per 1000 pregnancies.(1) Genitourinary tract malignancies have higher incidence as they are diagnosed by prenatal ultrasonographic examination.

Financial or Other, Competing Interest: None.

Submission 24-10-2016, Peer Review 17-11-2016,

Acceptance 23-11-2016, Published 28-11-2016.

Corresponding Author:

Dr. Kokila $K$,

No. 40/27,

Manika Vinayagar Koil Street,

Perambur,

Chennai-600039.

E-mail: anburules91@gmail.com

DOI: $10.14260 /$ jemds $/ 2016 / 1578$

\begin{abstract}
Objective
Our purpose was to retrospectively determine the histopathological nature of various neoplastic and nonneoplastic lesions associated with pregnancy and to ascertain the frequency and distribution of these lesions.
\end{abstract}

\section{MATERIALS AND METHODS}

We reviewed cases of pregnancy complicated by haemoperitoneum, masses and dysfunctional cysts in Institute of Obstetrics and Gynaecology over a five-year period with regards to clinical and pathological aspects. Our study population included all antenatal women with dysfunctional cysts, adnexal and non-adnexal masses. Masses were removed from 58 women at the time of caesarean section, 39 women during the antepartum period and were evaluated microscopically. Patients were followed up and followup information was recorded up to the date of last contact or death. 


\section{RESULTS}

A total of ninety seven cases were recorded and all these specimens were subjected for routine histopathological examination.

In this study, the incidence of these lesions were found to be 1.4/1000 deliveries. Of the total 97 women, 42 were primigravida, remaining were multigravida. Among 97 women, 59 were diagnosed during antenatal period and others were incidentally found at caesarean section. The average age range of the patient was 20-40 years. Mean time of diagnosis was 16-26 weeks of gestation. Mean time of surgical intervention was around 37-39 weeks. Asymptomatic women were found to have these lesions during caesarean section while remaining patients presented with abdominal pain, distension and haemoperitoneum. Histopathological diagnosis included dysfunctional cysts, uterine and cervical leiomyomas, benign ovarian surface epithelial tumours, ovarian germ cell tumours, angiomyolipoma, welldifferentiated hepatocellular carcinoma and Krukenberg tumour.

In this study, non-neoplastic cysts accounted for $25 \%$ cases. Among these cysts, paratubal/paraovarian cysts were common which is followed by haemorrhagic cyst, endometriotic cyst, follicular cyst and corpus luteal cyst.(2,3)
Most of these cystic lesions were incidental finding and cystectomy done during caesarean section. Lesions more than $5 \mathrm{~cm}$ presented with acute abdominal pain and showed features of torsion.

Neoplastic lesions constituted about $75 \%$ cases and include both benign and malignant tumours. $67 \%$ were benign and remaining $8 \%$ were malignant.

Leiomyoma complicating pregnancy was more frequently encountered compared to other benign and malignant conditions. 19 cases of uterine leiomyomas and 2 cases of cervical leiomyoma were reported. Pregnancy induced changes like red degeneration, hyaline degeneration and cystic degeneration were noted.(4)

Among benign surface epithelial ovarian neoplasm, serous cystadenoma predominated in comparison to mucinous cystadenomas.(5,6) 17 cases of benign cystic teratomas were recorded, of which one showed monodermal specialisation Struma ovarii.(7)

Dysgerminomas were the common malignant germ cell neoplasms. ${ }^{(8,9)}$ One case of mixed germ cell tumour (yolk sac tumour \& immature teratoma) and two cases of Krukenberg tumour were reported.(10)

A case of angiomyolipoma and hepatocellular carcinoma were recorded. $(11,12)$

\begin{tabular}{|l|c|c|}
\hline \multicolumn{1}{|c|}{$\begin{array}{c}\text { Clinical } \\
\text { Data }\end{array}$} & Number of Women & Percentage of Women \\
\hline Time at Diagnosis: & 12 & 12 \\
I trimester & 47 & 49 \\
II trimester & 38 & 39 \\
Caesarean section & & 40 \\
\hline Presenting Symptoms: & 39 & 60 \\
Symptomatic & 58 & 8 \\
Asymptomatic & & 32 \\
\hline Time at Surgical Intervention: & 31 & 60 \\
I trimester & 58 & \\
II trimester & & \\
Caesarean section $\quad$ Table 1. Time at Diagnosis, time at Surgical Intervention and Presenting Symptoms \\
\hline \multicolumn{2}{|c|}{} \\
\hline
\end{tabular}

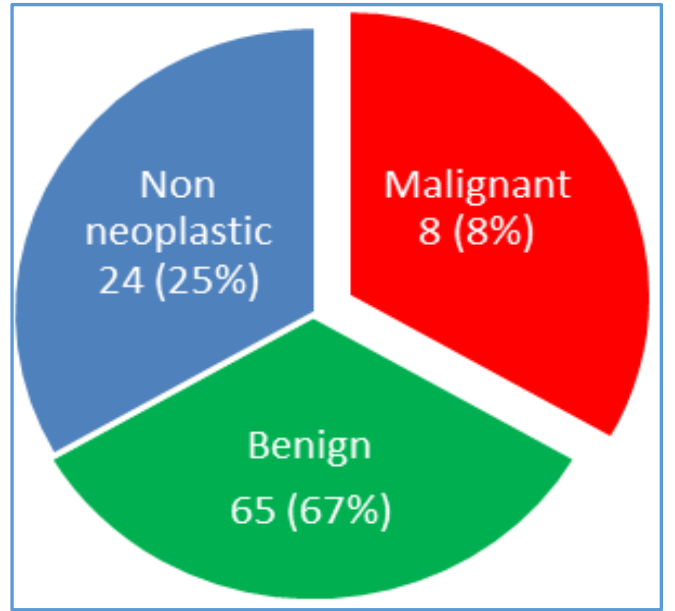

\begin{tabular}{|c|c|c|c|}
\hline $\begin{array}{c}\text { Histological } \\
\text { Diagnosis }\end{array}$ & $\begin{array}{c}\text { Number of } \\
\text { Women }\end{array}$ & $\begin{array}{c}\text { Age in } \\
\text { Years }\end{array}$ & $\begin{array}{c}\text { Size of } \\
\text { Cyst in } \\
\text { cm }\end{array}$ \\
\hline $\begin{array}{c}\text { Paratubal/ } \\
\text { Paraovarian cyst }\end{array}$ & 10 & $20-30$ & $2-12$ \\
\hline Haemorrhagic cyst & 5 & $20-30$ & $8-15$ \\
\hline Endometriotic cyst & 4 & $20-30$ & $3-13$ \\
\hline Follicular cyst & 2 & $20-35$ & $1.5 \& 8$ \\
\hline Corpus luteal cyst & 3 & $20-30$ & $2-3$ \\
\hline \multicolumn{4}{|c|}{ Table 2. Incidence of Non-neoplastic Lesions } \\
\hline
\end{tabular}

Proportion of Non-neoplastic and Neoplastic Lesions Complicating Pregnancy 


\begin{tabular}{|c|c|c|c|}
\hline Histological Diagnosis & Number of Women & Age in Years & Tumour Size in cm \\
\hline $\begin{array}{l}\text { Surface Epithelial Tumours: } \\
\text { Serous cystadenomas }\end{array}$ & 14 & $20-30$ & $1.5-20$ \\
\hline Papillary serous cystadenofibroma & 3 & $20-30$ & $3-15$ \\
\hline Benign mucinous cystadenoma & 7 & $20-35$ & $3.5-25$ \\
\hline $\begin{array}{c}\text { Sex Cord Stromal tumours: } \\
\text { Ovarian fibroma }\end{array}$ & 2 & $20-30$ & $12 \& 15$ \\
\hline $\begin{array}{l}\text { Germ Cell Tumours: } \\
\text { Benign cystic teratoma }\end{array}$ & 16 & $20-35$ & $6-12$ \\
\hline Monodermal/specialised teratoma, struma ovarii & 1 & 27 & 11 \\
\hline Dysgerminoma & 4 & $20-30$ & $16-22$ \\
\hline Mixed germ cell tumour & 1 & 23 & 25 \\
\hline Leiomyomas & 21 & $20-40$ & $3-15$ \\
\hline $\begin{array}{c}\text { Miscellaneous } \\
\text { Bilateral Krukenberg }\end{array}$ & 2 & $30-35$ & $10 \& 15$ \\
\hline Angiomyolipoma & 1 & 33 & 15 \\
\hline Hepatocellular CA & 1 & 32 & 2.5 \\
\hline \multicolumn{4}{|c|}{ Table 3. Incidence of Neoplastic Lesions } \\
\hline
\end{tabular}

\section{Outcome}

\begin{tabular}{|c|c|c|c|c|c|}
\hline Histological Diagnosis & \multicolumn{2}{|c|}{ Maternal Outcome } & \multicolumn{2}{c|}{ Foetal Outcome } \\
\hline & Alive & Expired & Lost to Followup & Alive & Expired \\
\hline Dysfunctional cyst & 24 & - & - & 24 & - \\
\hline Benign neoplasms & 65 & - & - & 65 & - \\
\hline Malignancy & 5 & 1 & 2 & 6 & 2 \\
\hline
\end{tabular}

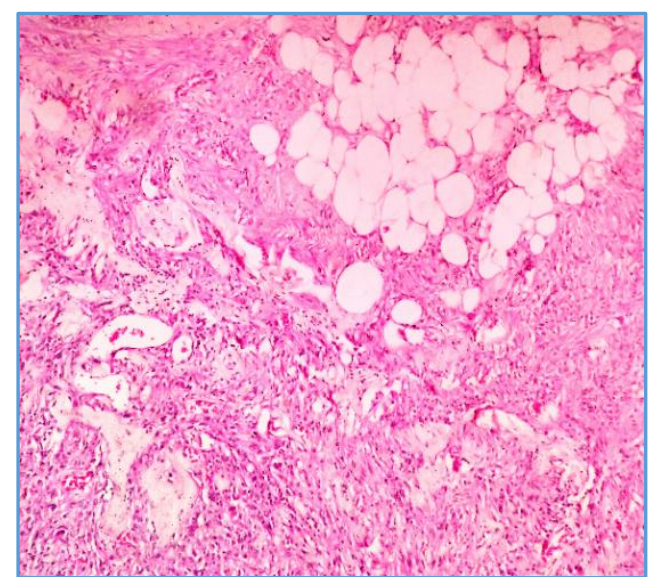

Figure 1. Angiomyolipoma: Composed of Variable Amounts of Adipose Tissue, Smooth Muscle and Blood Vessels. 400X H\&E

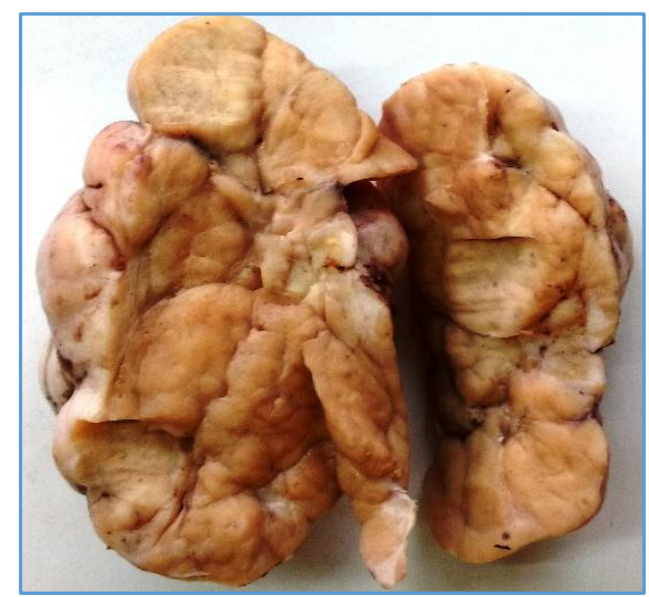

Figure 2. Dysgerminoma - Grossly Tumour is Solid, Fleshy and Lobulated

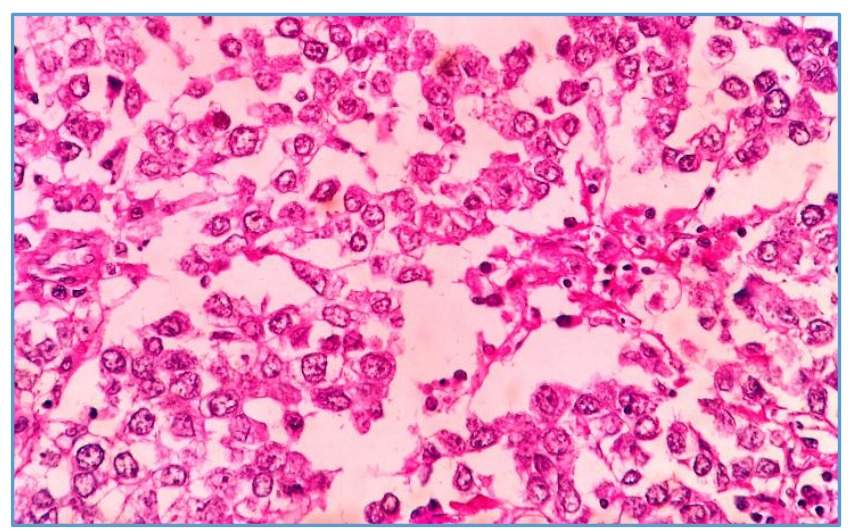

Figure 3. Dysgerminoma - Round to Polygonal Cells with Vesicular Nuclei \& Prominent Nucleoli. Stroma shows Numerous Lymphocytes. 400 X H\&E

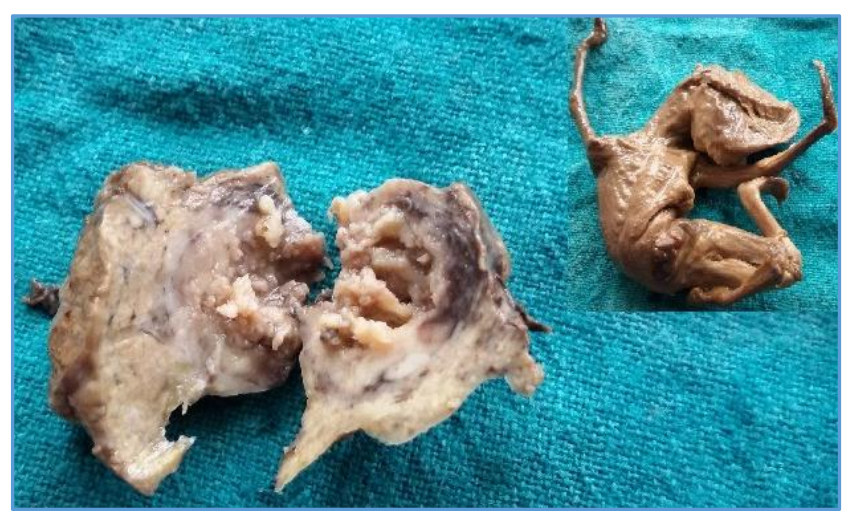

Figure 4. Hepatocellular Carcinoma - Tumour showing Rupture Site and Macerated Foetus that was Expelled Spontaneously 


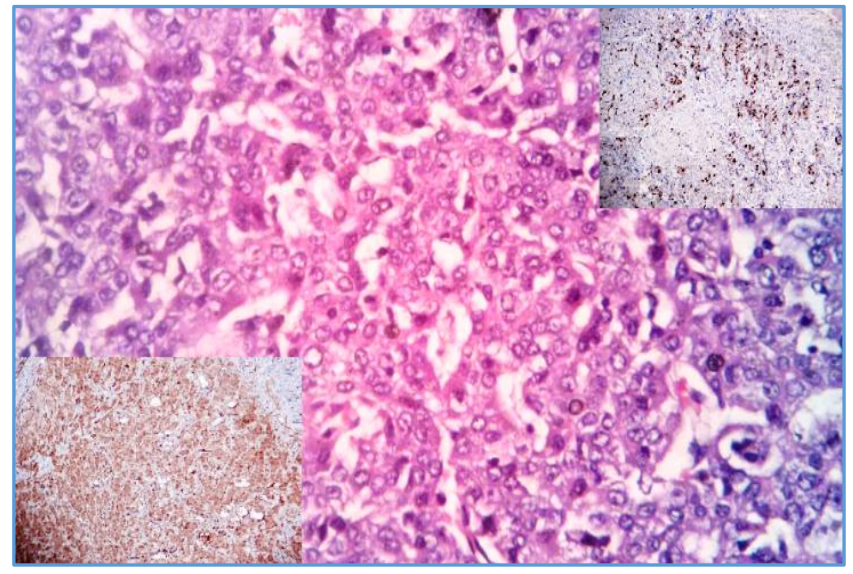

Figure 5. Hepatocellular Carcinoma - Tumour Cells showing Atypia and Few Mitotic Figures seen. 400X H\&E.

Upper Inset: Ki 67 Index showing more than 30\% Positivity in Tumour Cells. Lower Inset: Alpha Fetoprotein Positive in Tumour Cells

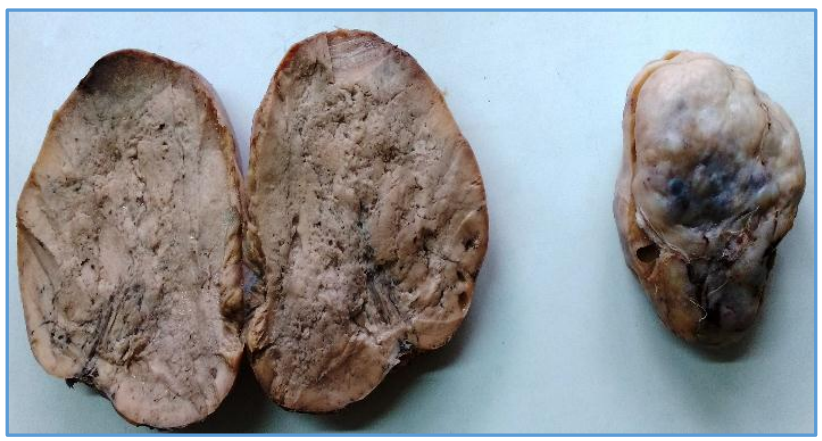

Figure 6. Krukenberg Tumour - Grossly Bilateral Solid Ovarian Mass

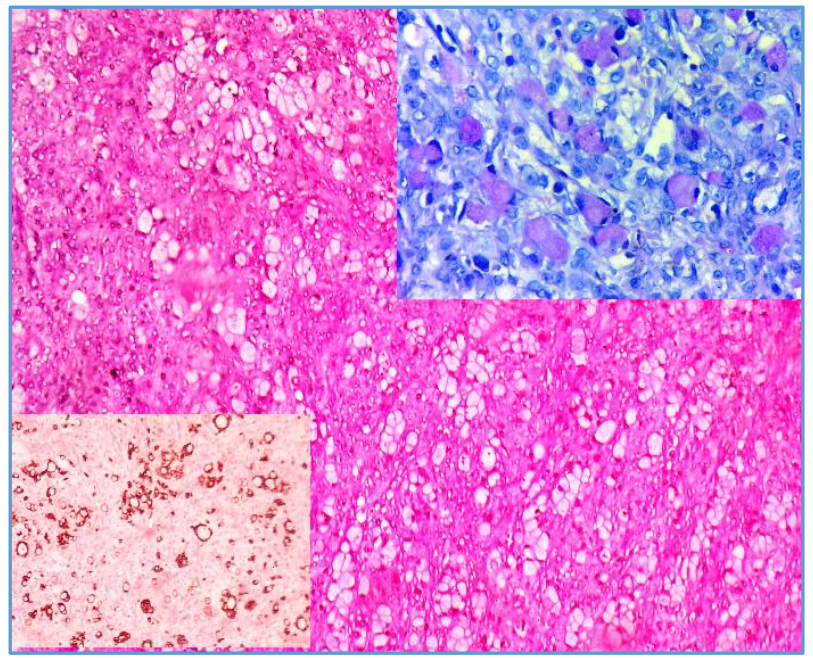

Figure 7. Krukenberg Tumour - Signet-ring of Cells which are PAS Positive \& CK 20 Positive

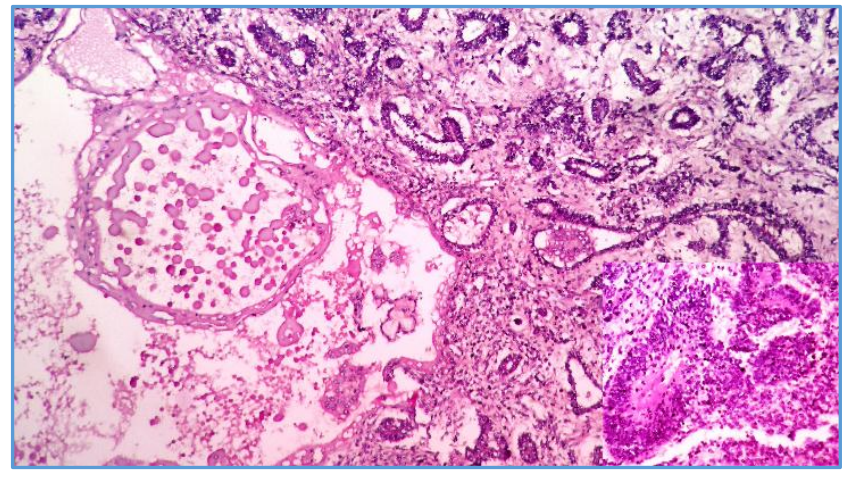

Figure 8. Mixed Germ Cell Tumour - Yolk Sac Elements with Hyaline Globules are seen. Lower Inset showing Immature Neuroepithelium

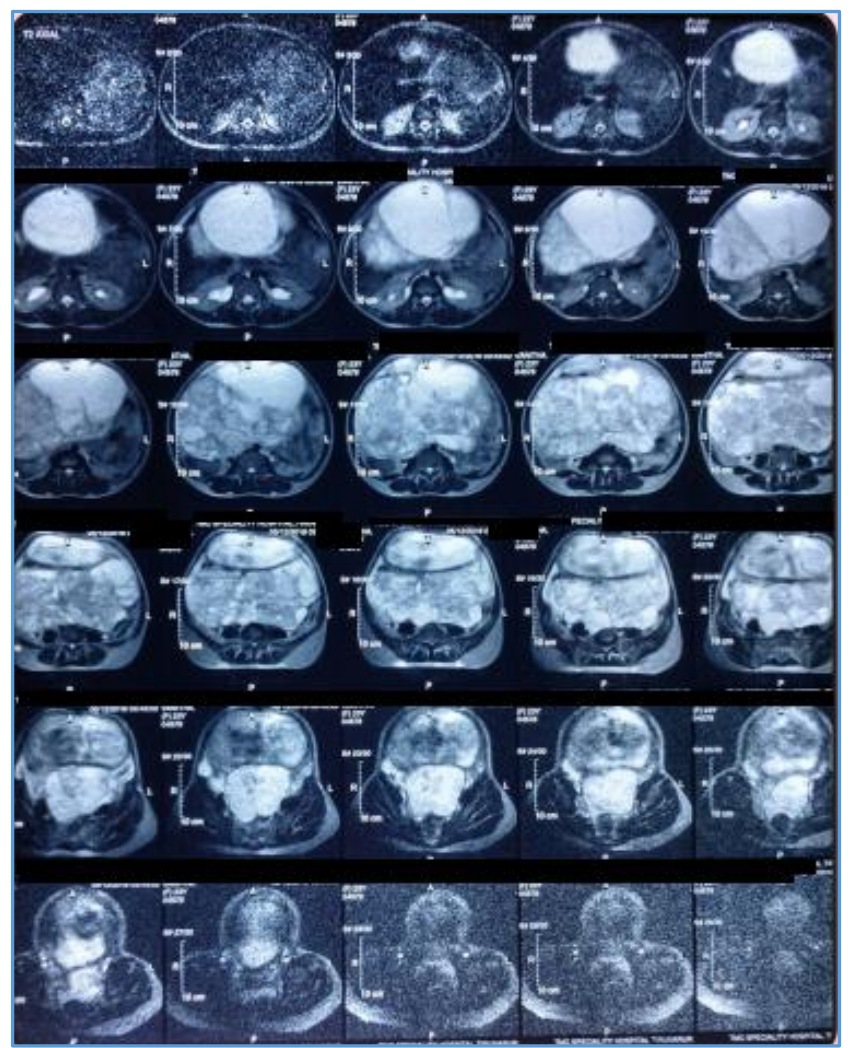

Figure 9. Mixed Germ Cell Tumour - MRI showing Solid and Cystic Right Ovarian Mass

\section{Maternal Outcome}

All women who underwent operative intervention for dysfunctional cysts and benign neoplasms were followed up and their post-operative period were uneventful. A case of hepatocellular carcinoma was treated with radiofrequency ablation and lost to followup after a period of two years. All four cases of dysgerminoma were in Stage I and three cases were in regular followup and one case lost to followup after a period of two years. One case of Krukenberg tumour with primary gastric carcinoma expired within three months of diagnosis. Another Krukenberg tumour which was found per operatively was evaluated for primaries and found to have growth in distal gastric region and referred at request to higher cancer institute for further management. A case of mixed germ cell tumour was followed up with tumour markers and patient was referred at request to higher cancer institute for further management. 


\section{Foetal Outcome}

The neonatal outcome in pregnancies complicated by dysfunctional cysts and benign neoplasms were good where as those complicated by malignant tumours had dismal prognosis. Pregnancies complicated by dysgerminoma and Krukenberg tumour had favourable foetal outcome. Mixed germ cell tumour patient delivered a female child weighing $800 \mathrm{~g}$ and succumbed to respiratory distress. Due to circulatory insufficiency, patient with hepatocellular carcinoma had spontaneous expulsion of foetus.

\section{DISCUSSION}

The overall incidence of ovarian masses in pregnancy was 2.4$5.7 \%$.(13) Of these masses, approximately $5 \%$ were malignant. Most patients with ovarian masses have no specific symptoms. This asymptomatic character of these lesions makes early diagnosis difficult. Currently, an ultrasound is routinely used early in pregnancy, and this has led to an early diagnosis and management of asymptomatic ovarian tumours. $(2,14)$

The management of these masses during pregnancy can be challenging for the clinician. The spectre of a possible malignancy can sway the decision for intervention versus expectant management. The aetiologies of ovarian masses were reflective of the patient's age; and therefore, benign entities such as dysfunctional ovarian cysts, benign cystic teratomas, and serous cystadenomas predominate. In the unusual cases when malignancy is present, they are typically germ cell and borderline ovarian tumours, and are commonly low stage and low grade.(15) Tumour markers are used primarily to monitor disease status after treatment rather than establishing diagnosis as a result of lack of specificity. Several studies have reported that the histologic types of ovarian masses during pregnancy were similar to those for non-pregnant women in the corresponding reproductive age group.(10)

Expectant management is recommended for most pregnant patients with asymptomatic, non-suspicious masses. Surgical intervention during pregnancy is indicated for large and/or symptomatic tumours and those that appear highly suspicious for malignancy on imaging. Conservative management is appropriate for benign masses and borderline ovarian tumours. Rarely, chemotherapy has been used during pregnancy when the risk of maternal mortality outweighs the foetal consequences.

The most common pregnancy associated adnexal masses were functional cysts like the corpus luteal cyst and theca lutein cysts. Most of these cysts will resolve after the first 14-16 weeks of gestation but some, like the theca lutein cysts, can persist until after delivery.(16) Masses that persist after 16 weeks of gestation were considered as non-functional. Most frequent complication was torsion and found to be associated with lesions greater than $5 \mathrm{~cm}$ in diameter.(16)

The majority of ovarian tumours associated with pregnancy were diagnosed at an early stage, when disease was still confined to the ovary.(10) Germ cell tumours and epithelial tumours of low malignant potential were much more prevalent than other types of malignancies in pregnancy.(17) Among epithelial tumours, serous cystadenomas were common followed by mucinous cystadenomas.(18) These epithelial tumours were of low malignant potential. Benign cystic teratoma was the most common benign germ cell tumour associated with pregnancy. Dysgerminoma was the most common malignant germ cell tumour followed by mixed germ cell tumours.(19)

Leiomyomas were the common uterine tumours associated with pregnancy and their incidence during pregnancy was approximately $2 \%$.(1) Leiomyomas vary in location and may develop as submucosal, subserosal, or intramural growths. Less frequently, these develop in cervix or broad ligament. In this series, two cases of cervical fibroid were reported and these were excised or else this would have caused cervical dystocia. Pregnancy induced changes like red degeneration, hyaline degeneration and cystic degeneration were noted.(4)

Common causes of spontaneous haemoperitoneum in pregnancy were ectopic pregnancy, ruptured ovarian cyst, endometriosis and uterine rupture. In this series, we reported two uncommon cases of spontaneous non-traumatic haemoperitoneum-angiomyolipoma and well-differentiated hepatocellular carcinoma. Hepatocellular carcinoma is very rare during pregnancy and has a worse prognosis in pregnant women compared to those who are not pregnant. Hepatocellular carcinoma is aggressive during pregnancy and has a poor prognosis with an overall one-year survival of $23 \%,(20)$ which could be explained by two main aetiologies: oestrogen elevation which accelerates the evolution of hepatocellular carcinoma and immune suppression during pregnancy.(21) It is associated with foetal loss in $42 \%$ of cases.(22)

In this series, we reported a case of well-differentiated hepatocellular carcinoma in which patient presented with haemoperitoneum at 20 weeks of gestation and a macerated foetus was expelled. Even though common cause of haemoperitoneum in pregnancy was ruptured ectopic, the possibility of bleeding intra-abdominal tumours should always be considered as a differential diagnosis in such clinical settings.

We reported two cases of Krukenberg tumour and these tumour accounts for $1-2 \%$ of all ovarian tumours. These tumours during pregnancy were even rarer, as the incidence of gastric cancer in women of reproductive age group was only $0.4 \%-0.5 \%{ }^{(23)}$

\section{CONCLUSION}

Pregnancy can be complicated by dysfunctional cysts and malignancies. Management of these conditions poses unique problems related to foetal outcome. Thus, a careful clinical examination helps in early diagnosis and treatment of such conditions. Even though common cause of haemoperitoneum in pregnancy is ruptured ectopic, the possibility of bleeding intra-abdominal tumours should always be considered as a differential diagnosis in such clinical settings.

\section{REFERENCES}

1. Cunningham FG, Leveno KJ, Bloom SL, et al. Williams obstetrics. 24th edn. McGraw Hill Professional 2014.

2. Whitecar MP, Turner S, Higby MK. Adnexal mass in pregnancy: a review of 130 cases undergoing surgical management. American Journal of Obstetrics and Gynecology 1999;181(1):19-24.

3. Hess LW, Peaceman A, O'Brien WF, et al. Adnexal mass occurring with intrauterine pregnancy: report of fifty-four patients requiring laparotomy for definitive management. American Journal of Obstetrics and Gynecology 1988;158(5):1029-34. 
4. Rice JP, Kay HH, Mahony BS. The clinical significance of uterine leiomyomas in pregnancy. American Journal of Obstetrics and Gynecology 1989;160(5 pt 1):1212-16.

5. Wang PH, Chao HT, Chiou-Chung Y, et al. Ovarian tumors complicating pregnancy. Emergency and elective surgery. The Journal of Reproductive Medicine 1999;44(3):279-87.

6. Ashkenazy M, Kessler I, Czernobilsky B, et al. Ovarian tumors in pregnancy. International Journal of Gynecology \& Obstetrics 1988;27(1):79-83.

7. Podratz KC, Field CS. Ovarian tumors during pregnancy. In: Cibils LA, ed. Surgical diseases in pregnancy. New York: Springer 1990:165-77.

8. Kwon YS, Mok JE, Lim KT, et al. Ovarian cancer during pregnancy: clinical and pregnancy outcome. Journal of Korean Medical Science 2010;25(2):230-4.

9. Horbelt D, Delmore J, Meisel R, et al. Mixed germ cell malignancy of the ovary concurrent with pregnancy. Obstetrics \& Gynecology 1994;84(4 pt 2):662-4.

10. Zanotti KS, Belinson JL, Kennedy AW. Treatment of gynecologic cancers in pregnancy. Semin Oncol 2000;27(6):686-98.

11. Fox LP, Stamm WJ. Krukenberg tumor complicating pregnancy: report of a case with androgenic activity. American Journal of Obstetrics and Gynecology 1965;92(5):702-10.

12. Garko SB, David OS, Mohammed T, et al. Hepatocellular carcinoma in pregnancy. Annals of African Medicine 2009;8(4):284-6.

13. Farahmand SM, Marchetti DL, Asirwatham JE, et al. Ovarian endodermal sinus tumor associated with pregnancy: review of the literature. Gynecol Oncol 1991;41(2):156-60.
14. Jacob JH, Stringer CA. Diagnosis and management of cancer during pregnancy. Semin Perinatol 1990;14(1):79-87.

15. Krukenberg F. Uber das fibrosarcoma ovarii mucocellulare (carcinomatoses). Archives of Gynecology and Obstetrics 1896;50:287-321.

16. Kumari I, Karur S, Mohan $\mathrm{H}$, et al. Adnexal masses in pregnancy: a 5 year review. Aust N Z J Obstet Gynaecol 2006:46(1):52-4.

17. Yanai H, Sasagawa I, Kubota Y, et al. Spontaneous hemorrhage during pregnancy secondary to renal angiomyolipoma. Urol Int 1996;56(3):188-91.

18. Akhtar K, Ahmad SS, Kumar A, et al. Dysgerminoma with pregnancy and viable baby: a case report. Oman Med J 2011;26(3):198-200.

19. Zalel Y, Piura B, Elchalal U, et al. Diagnosis and management of malignant germ cell ovarian tumors in young females. Int J Gynaecol Obstet 1996;55(1):1-10.

20. Leiserowitz GS. Managing ovarian masses during pregnancy. Obstet Gynecol Surv 2006;61(7):463-70.

21. El-Serag HB. Hepatocellular carcinoma. N Engl J Med 2011;365(12):1118-27.

22. Jonas MM. Hepatitis B and pregnancy: an underestimated issue. Liver Int 2009;29(Suppl 1):133-9.

23. Singhal SR, Nanda S, Chaudhry P, et al. Metastatic bilateral malignant ovarian tumors associated with pregnancy. Taiwanese Journal of Obstetrics and Gynecology 2009;48(2):167-8. 